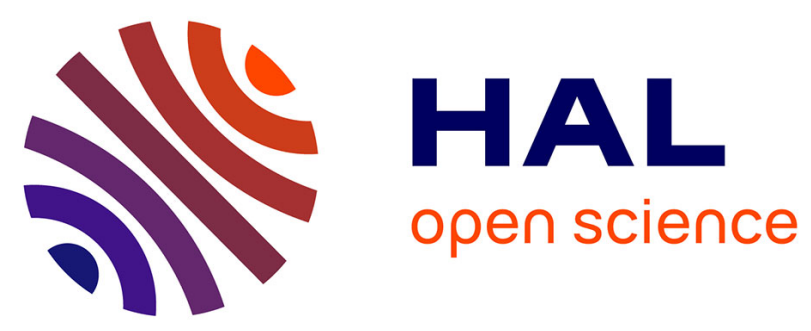

\title{
Impact of Vascular Calcifications on Long Femoropopliteal Stenting Outcomes
}

\author{
A. Kaladji, P.-A. Vent, A. Danvin, Philippe Chaillou, A. Costargent, B. \\ Guyomarch, T. Quillard, Y. Gouëffic
}

\section{- To cite this version:}

A. Kaladji, P.-A. Vent, A. Danvin, Philippe Chaillou, A. Costargent, et al.. Impact of Vascular Calcifications on Long Femoropopliteal Stenting Outcomes. Annals of Vascular Surgery, 2018, 47, pp.170-178. 10.1016/j.avsg.2017.08.043 . hal-01713545

HAL Id: hal-01713545

https://hal-univ-rennes1.archives-ouvertes.fr/hal-01713545

Submitted on 28 Feb 2018

HAL is a multi-disciplinary open access archive for the deposit and dissemination of scientific research documents, whether they are published or not. The documents may come from teaching and research institutions in France or abroad, or from public or private research centers.
L'archive ouverte pluridisciplinaire HAL, est destinée au dépôt et à la diffusion de documents scientifiques de niveau recherche, publiés ou non, émanant des établissements d'enseignement et de recherche français ou étrangers, des laboratoires publics ou privés. 
1 Original article

2 Impact of vascular calcifications on long femoropopliteal stenting

\section{3 outcomes}

4 Adrien Kaladji ${ }^{1,2,3}$, Pierre-Alexandre Vent ${ }^{4}$, Aurore Danvin ${ }^{4,5}$, Philippe Chaillou ${ }^{4}$, Alain

5 Costargent ${ }^{4}$, Béatrice Guyomarch ${ }^{6,7,8}$, Thibaut Quillard ${ }^{5}$, Yann Gouëffic ${ }^{4,5,8}$

6 1. Rennes University Hospital, Centre of Cardiothoracic and Vascular Surgery, F-35033

7 Rennes, France

$8 \quad 2 . \quad$ INSERM, U1099, F-35000 Rennes, France

9 3. University Rennes 1, Signal and Image Processing Laboratory (LTSI), F-35000

10 Rennes, France

11 4. Nantes University Hospital, Thorax Institute, Vascular Surgery Department, Nantes, 12 F-44093 France

13 5. Laboratory of Pathophysiology of Bone Resorption, UMR-957, Nantes, F-44000

14 France

15 6. Inserm UMR1087, Thorax Institute, Nantes, F-44000 France

$167 . \quad$ CNRS, UMR 6291, Nantes, F-44000 France

17 8. University of Nantes, Nantes, F-44000 France

18 Corresponding author:

19 Adrien Kaladji, Centre of Cardiothoracic and Vascular Surgery, Rennes University Hospital, 20 F-35033 Rennes, France

21 kaladrien@hotmail.fr

22

23 Word count : 2651 
ABSTRACT (word count: 391)

Objective: Vascular calcifications (VCs) may be a prognostic factor for outcome after endovascular treatment of peripheral arterial disease (PAD). Semi-quantitative analysis with X-ray imaging is the main limiting factor for assessing VCs. The aim of the present study was to find a correlation between the amount of VC with a CT scan quantification and mid-term results of endovascular treatment of TASC C/D femoropopliteal (FP) lesions.

Methods: Patients belonging to two previously published registries (STELLA and STELLA PTX) and who underwent a preoperative CT scan were retrospectively included in the study. VC quantification was performed with a dedicated workstation (EndoSize, Therenva) on the basis of Hounsfield units (HU). The VC percentage was calculated as the ratio between VC volume and the volume of the region of interest. For the analysis, patients were divided into three groups according to VC percentage, from lowest to highest: group 1 (G1) included the 1st quartile of VCs, group 2 (G2) included the 2nd and 3rd quartiles and group 3 (G3) included the 4th quartile. Risk of in-stent thrombosis was analysed using a multivariate model.

Results: Thirty-nine patients were included (10 in G1, 19 in G2, 10 in G3) and mean followup duration was $24 \pm 14.6$ months. Patients in G1 and G3 had, respectively, a VC rate of $<1 \%$ (no VC) and >20\% (severe VC). In G2, VC was considered to be intermediate. There was no statistical difference in the cardiovascular risk factors and preoperative medication. A significant difference was found for the healthy FP diameter between G1 (4.6 $\pm 0.8 \mathrm{~mm})$ and G3 $(6.8 \pm 0.8 \mathrm{~mm}, \mathrm{p}<0.0001)$ and between G2 $(5.2 \pm 1 \mathrm{~mm})$ and $\mathrm{G} 3(\mathrm{p}<0.0001)$. The rate of drug-eluting stents was similar in all groups. There was no difference between groups 
50

concerning the rate of in-stent restenosis, target lesion revascularisation and target extremity

51 revascularisation. There was a higher rate of in-stent thrombosis for G1 vs. G2 (p=0.037) and no difference was noted between G1 vs. G3 (p=0.86) or G2 vs. G3 (p=0.12). G3 was

\section{3}

57 stent thrombosis 
66

67

\section{Introduction}

The most common cause of peripheral arterial disease is atherosclerosis. Despite being exposed to similar risk factors, peripheral arteries develop heterogeneous atherosclerotic lesions. Our previous work showed that carotid arteries develop predominantly lipid-rich lesions and microcalcifications, while femoral arteries develop fibrotic lesions, with extensive vascular calcification (VC) and frequent presence of osteoid tissue (1-4). These differences may have major clinical implications. Firstly, VC may destabilise atheromatous plaques and contribute to plaque rupture (5-7). Moreover, advanced and extensive VC contributes to arterial stiffness and hypertension, an important risk factor for plaque rupture $(8,9)$.

Secondly, the presence of VC may influence the technical success rate and outcomes of peripheral endovascular procedures (10). It is noteworthy that severe VC is often considered an exclusion criterion in femoropopliteal clinical study protocols. Moreover, balloon angioplasty of severe calcified lesions is limited by early elastic recoil and poor acute and long-term outcomes (11). Although nitinol stents are designed to prevent elastic recoil and constrictive remodelling, severe VC may prevent stent expansion, resulting in poorer outcomes when compared to fully expanded stents (12). Also, it seems that VC may influence the efficacy of drug-eluting balloons during revascularisation of femoropopliteal lesions, mainly in cases of circumferential distribution (13).

Nevertheless, few data are available to determine the influence of VC on femoropopliteal endovascular treatment outcomes. In the present study, we sought to determine the perioperative and mid-term outcomes following long femoropopliteal stenting according to preoperative VC burden. 
89

90

91

92

93

94

95

96

97

98

99

100

101

102

103

104

105

106

107

108

109

110

111

112

113

\section{Patients and Methods}

Population

Patients included in this study belong to two published prospective registries $(14,15)$. Briefly, the patients presented with femoropopliteal lesions $\geq 15 \mathrm{~cm}$ (TASC II C and D) and were enrolled as soon as the guide crossed the lesion. The first patient cohort (STELLA study) was treated with a LifeStent ${ }^{\circledR}$ bare metal stent (Bard Peripheral Vascular, Tempe, AZ, USA) and was enrolled between November 2008 and October 2009. The second patient cohort was treated with a Zilver ${ }^{\circledR}$ PTX ${ }^{\circledR}$ paclitaxel-eluting stent (STELLA PTX study) (16) (16) (16) (16) (16) (16) (Cook Peripheral Vascular, USA) and was enrolled between March 2011 and April 2012. The inclusion/exclusion criteria and the endovascular procedures were identical for both groups and have already been reported in the STELLA and STELLA PTX studies. Protocols were approved by local ethics committees and all patients gave their informed consent.

\section{CTA analysis and quantification of VC}

All computed tomography angiograms (CTAs) were analysed with a dedicated workstation (17-20) (EndoSize ${ }^{\circledR}$, Therenva, France) by one investigator blinded to outcomes. Centrelines from the common femoral artery to the end of the popliteal artery (Fig. 1A) were manually extracted for femoropopliteal occlusions, otherwise automatic extraction was used (in case of stenosis). A region of interest (ROI) was determined as a cylinder centred around centrelines (Fig. 1B) whose diameter was manually adjusted to ensure all VC was included. Within the ROI, a dedicated program allowed segmentation of both arterial lumen (ALu) and VC

(Fig. 1C-D) with a thresholding tool. The difference between ALu and VC was based on HU density (21-23): voxels in the range 400-3000 HU were considered VC (and quantified in $\mathrm{mm}^{3}$ ) whereas voxels in the range 100-400 HU were considered ALu (Fig. 1C-D). Volume of 
114 VC and ALu were calculated for the entire femoropopliteal artery but also at the level of the

115 treated segment. The percentage of VC and ALu at the level of the treated segment was

116 determined by the ratio between the volume of VC and ALu and the volume of the ROI. The

117 other CTA parameters analysed were the length of lesions and the diameter of the healthy

118 superficial femoral artery.

119

120

Definition of groups

121 In order to compare pre-, peri- and post-operative data according to the amount of VC, 3

122 groups were established. The overall population was divided according to the rate of VC,

123 from the lowest to the highest percentage of VC: group 1 (G1) included the 1st quartile of

124 VC, G2 included the 2nd and 3rd quartiles and G3 included the 4th quartile.

Follow-up

127 Follow-up consisted of a clinical examination, measurement of ankle-brachial index (ABI)

128 and a duplex scan at 1, 3, 6, 9, 12, 18 months then annually thereafter. An X-ray of the thighs

129 with two separate incidences of at least $45^{\circ}$ was taken after 12 months in order to test for stent

130 fracture. All of the data were entered in a prospective follow-up register.

132 Endpoints

133 The primary endpoint compared between groups was in-stent thrombosis during follow-up.

134 Secondary endpoints were target lesion revascularisation (TLR), target extremity 135 revascularisation (TER) and in-stent restenosis (ISR). Endpoint definitions have already been 136 described in articles reporting on the respective results recorded for both cohorts, and comply 137 with international definitions. 
139 Statistical analysis

140 Continuous variables were presented as mean \pm SD and categorical variables as count and

141 percentages. Pearson's chi-square test was used for comparisons of continuous variables, and

142 one-way factorial ANOVA for categorical data after testing the normality of the data, and

143 then differences among means were analysed using post-hoc Tukey-HSD or Games-Howell

144 multiple comparison tests depending on the results of the assumption of homogeneity of

145 variances (Levene test). A correlation between SFA diameter and amount of VC was

146 calculated by use of the Pearson correlation coefficient. Postoperative outcomes were

147 compared between groups using the log-rank test. A predictive model was developed to

148 demonstrate any correlation between pre/perioperative factors and stent thrombosis. Inclusion

149 of variables in the model with $\mathrm{p}<0.1$ (or forced-in) were based on the Pearson's chi-square

150 test for categorical variables and ANOVA for continuous variables. A multivariate analysis

151 implemented using a Cox model with a stepwise descending procedure was fitted. A p value

$152<0.05$ was considered statistically significant. Data were analysed using SPSS software

153 (SPSS Inc., Chicago, IL, USA).

154

155 


\section{Results}

157 Demographic data

158 Of the 103 patients of both registries, only those with preoperative computed tomography angiography (CTA) were included. Patients with only a duplex scan (n=29), magnetic

160

161 resonance angiography $(n=25)$ or without a CTA $(n=10)$ were excluded from the study. Thirty-nine patients were therefore included for analysis. Every patient in group 1 had a VC rate in the lesion area of $<1 \%$; this group was therefore considered the non-calcified group $(n=10)$. Patients in group 3 had a VC rate $>20 \%$; this group was considered the heavily calcified group ( $\mathrm{n}=10)$. Group 2 consisted of patients with a VC rate in the range $1-20 \%$ and was considered as the intermediate calcification group $(\mathrm{n}=19)$.

As shown in Table 1, there was no difference in demographic characteristics between groups, except a significantly higher rate of hyperlipidaemia in group $3(\mathrm{p}=0.008)$. Statin therapy rates were not different.

Lesions and intraoperative data (Table 2)

With regard to anatomical characteristics of the femoropopliteal segment, it was noted that the diameter was different between groups with the ANOVA test, and post-hoc tests revealed that this difference was significant between group 1 and $3(\mathrm{p}<0.0001)$ and between group 2 and 3 $(\mathrm{p}=0.0002)$. There was no difference between group 1 and $2(\mathrm{p}=0.217)$. A significant correlation was found between femoropopliteal segment diameter and the amount of VC (Fig. 2). Given the fact that groups were determined according to VC rate, a significant difference was found between them for Ca and ALu volume in the lesion area and for the overall femoropopliteal segment. With regard to endovascular treatment, no difference was observed for characteristics of implanted stents nor for use of X-ray and contrast load. 
181 During follow-up, 10 (25.6\%) stent thromboses occurred (Table 3): 4 (40\%) in group 1, 2

182 (10.5\%) in group 2 and 4 (40\%) in group 3. According to the log rank test, this rate was

183 statistically different between group 1 vs. 2 but not between group 2 vs. 3 and group 1 vs. 3 .

184 When the date of occurrence of stent thrombosis was analysed (Fig. 3), a trend was shown:

185 heavy Ca was associated with early stent thrombosis, while no Ca was associated with late

186 stent thrombosis. More precisely, heavy Ca presented a stent thrombosis at 1 month while

187 every patient with no Ca presented a stent thrombosis between the 6th and the 24th months.

188 All patients with intermediate Ca presented a stent thrombosis after the 48th month. Rates of

189 in-stent restenosis, TLR and TER are provided in Table 3 and were not statistically different 190 between groups.

191

192 Risk factor for in-stent thrombosis

193 Results of the univariate/multivariate analysis are provided in Tables 4 and 5. On univariate

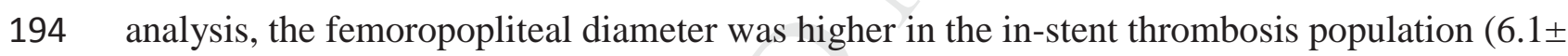

1951.3 mm vs. $5.2 \pm 1.1, \mathrm{p}=0.05$ ) but on multivariate analysis it did not appear to be significant,

196 although a trend towards a protective effect of the femoropopliteal diameter on in-stent

197 thrombosis was noted (Table 5). The other variables included in the multivariate analysis

198 were sex, hypercholesterolaemia and calcification (according to groups). Only VC appeared

199 to significantly influence in-stent thrombosis. Patients belonging to group 2, i.e. with an

200 intermediate calcification rate, seemed to be protected from in-stent thrombosis with an odds

201 ratio of 0.27 (95\% confidence interval: 0.1-0.77; $\mathrm{p}=0.014$ ). 
205 In this study, we report that the rate of VC has a high impact on endovascular treatment outcomes after long femoropopliteal stenting. Given that a high amount of VC is frequently an exclusion criterion, few data are available concerning results of endovascular therapies in calcified arteries because it is assumed that outcomes are poor with this specific arterial feature. In this paper, we sought to determine the role of VC after stent implantation. It seems that, as assumed, a high rate of VC is at risk of technical failure and poor outcomes but also arteries with no calcification. An intermediate rate of VCs may protect against in-stent

212 thrombosis.

\section{Classification}

214 Currently, neither quantitative nor qualitative preoperative VC assessment is available in 215 routine practice. Indeed, current VC quantitative grading is based on subjective, semiquantitative, angiographic- and fluoroscopic-based assessments. Furthermore, VC nature and composition cannot be determined by current non-invasive methods. Among non-invasive preoperative imaging methods, CTAs are still more available and cheaper than magnetic resonance angiographies and are widely used in current practice. Two previously published

220 grading systems are often used in studies to assess VC but the quantification is based on 221 angiographic images and remains subjective (24, 25). In 2014, Rocha-Singh et al. (25)

222 proposed a peripheral arterial calcium scoring system (PACSS) and a method for its clinical 223 validation. In this classification, the scoring system takes into account the pathological 224 location of calcification (intima, media, combined) along with the location and length of the 225 affected segment and is based on angiographic assessment. Correlation of this grading system 226 with procedure and patient outcomes is currently under evaluation. Dattilo et al. reported an 227 angiographic calcium score and used fluoroscopic images to quantify VC but the 228 circumference of VC was determined by an anteroposterior view, raising the question of the 
229 accuracy of this quantification. In cardiology literature, optical coherence tomography (OCT)

230 has been reported to assess VC and stent expansion. In this particular study, a high rate of VC

231 was found to be a factor for stent underexpansion (26). Although algorithms for segmenting

232 VC on CT images have existed for decades, they have only been reported in clinical papers

233 since Ohana et al. (23). They proposed an alternative to the Trans-Atlantic Inter-Society

234 Consensus Document II on Management of Peripheral Arterial Disease classification (TASC

235 II)(27) based on the mean occluded diameter and percentage of calcifications. Calcification

236 volume determined by a colour-coded map provided an accurate estimate but no correlation

237 with clinical or morphological outcomes was given. Our assessment method was similar to

238 that of Ohana et al. but, in both cases, CTA did not allow intimal and medial calcifications to

239 be distinguished. Medial calcifications, known as Mönckeberg's medial calcinosis, are

240 associated with type II diabetes and chronic kidney disease and represent a specific pattern of

241 VC with a distinct pathological type of calcification that may contribute to arterial stiffness

242 (28).

244 Lesions and intraoperative data

245 With regard to lesions and intraoperative data, we observed that VCs were associated with a

246 larger femoropopliteal diameter. Enlargement of femoropopliteal arteries was probably linked

247 to positive vessel remodelling. Indeed, during the atherosclerotic process, femoral arteries

248 may locally develop compensatory enlargement to compensate for lumen narrowing by

249 plaque formation (29). Consequently, we can assume that positive femoropopliteal

250 remodelling could be associated with a greater amount of VCs. 
253 Occurrence of in-stent thrombosis at 1 month is significantly higher in most calcified groups.

254 Vascular calcifications are known to represent a technical challenge for interventionalists as

255 they may make artery recanalisation difficult and may promote technical failure leading to a

256 perioperative in-stent thrombosis. Different types of technical failure were observed during

257 long femoropopliteal recanalisation such as non-expansion of self-expandable stents, stent

258 malapposition or plaque fracture leading to local thrombosis. It is noteworthy that severe VC

259 is often considered an exclusion criterion for femoropopliteal clinical trials (30, 31) but, so

260 far, few data have been available to state that severe VCs are a predictive factor for poor

261 morphological success at 1 month.

263 Mid-term in-stent thrombosis and restenosis with soft plaques

264 The multivariate analysis concluded that patients with intermediate VCs are less likely to 265 present an in-stent thrombosis during follow-up in comparison to others. Indeed, patients with severe VC presented in-stent thrombosis during the perioperative period and patients with soft

267 plaques were at risk of in-stent thrombosis at mid-term. Analysis of in-stent thrombosis

268 timing suggests that the in-stent thrombosis mechanism may be different. Technical failure, as 269 described above, may be the main cause of perioperative in-stent thrombosis. However, for a 270 longer follow-up, a biological factor may explain in-stent thrombosis. Therefore, this

271 observation may suggest that lesions with a low amount of VC are an entity at risk of

272 complications following endovascular revascularisation. This hypothesis derives from

273 fundamental research where it was recently found that osteoprotegerin (OPG) and osteoid

274 metaplasia (OM) were associated with carotid plaque stability (1). In this study, a

275 significantly higher presence of OM, OPG and pericytes was noted in asymptomatic

276 compared to symptomatic plaques. Without femoropopliteal plaque analysis, these results

277 cannot be transposed and a plaque accident is not similar to a stent thrombosis but it can be 
278 assumed that femoropopliteal VC could have the same behaviour on the stented plaque as the

279 carotid plaque. An interesting study on coronary arteries failed to show that severely calcified

280 arteries have a lower rate of in-stent restenosis whereas the working assumption was based on

281 previous histological findings (32). The authors noted that restenosis is composed of

282 neointimal hyperplasia derived from smooth muscle cells and fibroblasts migrating from the

283 vessel wall. Since normal components of calcific arterial walls are largely replaced by

284 calcium deposits and fibrosis, the authors suggested that stented calcific arteries would

285 restenose less than non-calcified arteries. Finally, despite the potential role played by

286 calcifications, it has been shown also in coronary artery disease that a pathophysiological

287 process characterized by impaired endothelial coverage, persistent fibrin deposition, and

288 ongoing vessel wall inflammation contribute to late in stent thrombosis(33).

\section{Limitations}

291 The main limitation of this study is obviously the number of patients enrolled. Although

292 statistical tests designed for small samples were used, a greater number of patients would

293 probably have highlighted other differences between the groups. For that reason, the results of

294 the multivariate analysis should be interpreted with caution. It is probably more appropriate to

295 conclude that we found a trend more than there is clearly a significant difference between

296 groups. Moreover, the rate of stent thrombosis is especially high in this study but does not

297 reflect the rate found in both registries. As a reminder, the rate if in-stent thrombosis at one

298 year was $11.3 \%$ and $14.6 \%$ in STELLA and STELLA PTX registries respectively. But in the

299 paper of Bosier et al(34), this rate was $24 \%$ at one year, almost similar to our study (25.6\%).

300 Grouping of both registries may also be interpreted as a bias because bare metal stent (BMS)

301 and drug-eluting stent (DES) outcomes have been mixed. However, it can be observed that

302 the DES rate was similar in all groups and recently, we have shown with a propensity score- 
303

matched analysis that, according to both registries, paclitaxel-eluting stents do not seem to

304 results.

provide benefits in terms of clinical and morphological outcomes for TASC C/D lesions compared to bare metal stent(35). Moreover, there is an heterogeneity in the dual antiplatelet therapy (DAPT) prescription in the present cohort and even though there is no high level of evidence for DAPT after peripheral endovascular stenting, coronary studies recommended DAPT systematically for a minimum duration of 6 months to prevent in stent thrombosis(36).

Our working hypothesis needed to focus on two different lesions in terms of plaque composition: these were no VC and severe VC. The rate of VC according to median values ultimately showed that group composition was appropriate to our objective to compare essentially no Ca and severe Ca. The intermediate VC group including the 2nd and 3rd quartiles of the entire population corresponds to the "moderate" group in many studies using a 3-grade VC classification. We do not support that four grades of VC classification would be relevant since our hypothesis was that no and severe VC groups are of interest and leads to different outcomes with different mechanisms.

\section{Conclusion}

This study showed that an accurate quantification of VC is interesting to assess endovascular outcomes after stenting of FP lesions. It seems that both absence and heavily calcifications are at risk of in-stent thrombosis. Calcification of a certain quantity and quality may be necessary for plaque stability. Additional data with a larger population are mandatory to confirm these 


\section{Conflict of interest}

327 Yann Gouëffic: Boston Scientific, Cook, Hexacath, Medtronic, Perouse.

328

329

330 


\section{$331 \quad$ Funding}

332 None

333 


\section{Acknowledgements}

335 The authors are indebted to the INSERM 1414 Clinical Investigation Centre, Innovative

336 Technology (Rennes, F-35000, France) for its support in the processing of the imaging data.

337 We thank Carine Montagne and Manon Pondjikli for their excellent technical support.

338

339 


\section{References}

342

343 1. Davaine JM, Quillard T, Brion R, Laperine O, Guyomarch B, Merlini T, et al.

344 Osteoprotegerin, pericytes and bone-like vascular calcification are associated with carotid 345 plaque stability. PLoS One 2014;9:e107642.

346 2. Davaine JM, Quillard T, Chatelais M, Guilbaud F, Brion R, Guyomarch B, et al. Bone 347 Like Arterial Calcification in Femoral Atherosclerotic Lesions: Prevalence and Role of 348 Osteoprotegerin and Pericytes. Eur J Vasc Endovasc Surg 2016;51:259-67.

349 3. Goueffic Y, Davaine JM, Merlini T, Rimbert A, Herisson F, Heymann MF, et al. 350 [Arterial heterogeneity]. Rev Med Interne 2013;34:61-5.

351 4. Herisson F, Heymann MF, Chetiveaux M, Charrier C, Battaglia S, Pilet P, et al. 352 Carotid and femoral atherosclerotic plaques show different morphology. Atherosclerosis $353 \quad 2011 ; 216: 348-54$.

354 5. Kelly-Arnold A, Maldonado N, Laudier D, Aikawa E, Cardoso L, Weinbaum S. 355 Revised microcalcification hypothesis for fibrous cap rupture in human coronary arteries. 356 Proc Natl Acad Sci U S A 2013;110:10741-6.

357 6. Maldonado N, Kelly-Arnold A, Cardoso L, Weinbaum S. The explosive growth of 358 small voids in vulnerable cap rupture; cavitation and interfacial debonding. J Biomech $3592013 ; 46: 396-401$.

360 7. Maldonado N, Kelly-Arnold A, Vengrenyuk Y, Laudier D, Fallon JT, Virmani R, et 361 al. A mechanistic analysis of the role of microcalcifications in atherosclerotic plaque stability: 362 potential implications for plaque rupture. Am J Physiol Heart Circ Physiol 2012;303:H61928. 
8. Joly L, Mandry D, Verger A, Labat C, Watfa G, Roux V, et al. Influence of Thoracic Aortic Inflammation and Calcifications on Arterial Stiffness and Cardiac Function in Older Subjects. J Nutr Health Aging 2016;20:347-54.

9. Pikilidou M, Yavropoulou M, Antoniou M, Yovos J. The Contribution of Osteoprogenitor Cells to Arterial Stiffness and Hypertension. J Vasc Res 2015;52:32-40. 10. Shin SH, Baril D, Chaer R, Rhee R, Makaroun M, Marone L. Limitations of the Outback LTD re-entry device in femoropopliteal chronic total occlusions. J Vasc Surg 2011;53:1260-4.

11. Capek P, McLean GK, Berkowitz HD. Femoropopliteal angioplasty. Factors influencing long-term success. Circulation 1991;83:I70-80.

12. Bausback Y, Botsios S, Flux J, Werner M, Schuster J, Aithal J, et al. Outback catheter for femoropopliteal occlusions: immediate and long-term results. J Endovasc Ther 2011;18:13-21.

13. Fanelli F, Cannavale A, Gazzetti M, Lucatelli P, Wlderk A, Cirelli C, et al. Calcium burden assessment and impact on drug-eluting balloons in peripheral arterial disease. Cardiovasc Intervent Radiol 2014;37:898-907.

14. Davaine JM, Azema L, Guyomarch B, Chaillou P, Costargent A, Patra P, et al. Oneyear clinical outcome after primary stenting for Trans-Atlantic Inter-Society Consensus (TASC) C and D femoropopliteal lesions (the STELLA "STEnting Long de L'Artere femorale superficielle" cohort). Eur J Vasc Endovasc Surg 2012;44:432-41.

15. Davaine JM, Querat J, Kaladji A, Guyomarch B, Chaillou P, Costargent A, et al. Treatment of TASC C and D Femoropoliteal Lesions with Paclitaxel eluting Stents: 12 month Results of the STELLA-PTX Registry. Eur J Vasc Endovasc Surg 2015;50:631-7. 16. Davaine JM, Querat J, Kaladji A, Guyomarch B, Chaillou P, Costargent A, et al. Treatment of TASC C and D Femoropoliteal Lesions with Paclitaxel eluting Stents: 12 month 
389

390

391

392

393

394

395

396

397

398

399

400

401

402

403

404

405

406

407

408

409

410

411

412

413

Results of the STELLA-PTX Registry. European journal of vascular and endovascular

surgery : the official journal of the European Society for Vascular Surgery 2015;50:631-7.

17. Kaladji A, Lucas A, Kervio G, Haigron P, Cardon A. Sizing for endovascular aneurysm repair: clinical evaluation of a new automated three-dimensional software. Ann Vasc Surg 2010;24:912-20.

18. Boufi M, Aouini F, Guivier-Curien C, Dona B, Loundou AD, Deplano V, et al.

Examination of factors in type I endoleak development after thoracic endovascular repair. J Vasc Surg 2015;61:317-23.

19. Zerwes S, Nurzai Z, Leissner G, Kroencke T, Bruijnen HK, Jakob R, et al. Early experience with the new endovascular aneurysm sealing system Nellix: First clinical results after 50 implantations. Vascular 2016;24:339-47.

20. Zhang Y, Tang H, Zhou J, Liu Z, Liu C, Qiao T, et al. The imaging assessment and specific endograft design for the endovascular repair of ascending aortic dissection. Clin Interv Aging 2016;11:933-40.

21. Komatsu S, Hirayama A, Omori Y, Ueda Y, Mizote I, Fujisawa Y, et al. Detection of coronary plaque by computed tomography with a novel plaque analysis system, 'Plaque Map', and comparison with intravascular ultrasound and angioscopy. Circ J 2005;69:72-7.

22. Obaid DR, Calvert PA, Gopalan D, Parker RA, West NE, Goddard M, et al. Dualenergy computed tomography imaging to determine atherosclerotic plaque composition: a prospective study with tissue validation. J Cardiovasc Comput Tomogr 2014;8:230-7.

23. Ohana M, El Ghannudi S, Girsowicz E, Lejay A, Georg Y, Thaveau F, et al. Detailed cross-sectional study of 60 superficial femoral artery occlusions: morphological quantitative analysis can lead to a new classification. Cardiovasc Diagn Ther 2014;4:71-9.

24. Dattilo R, Himmelstein SI, Cuff RF. The COMPLIANCE 360 degrees Trial: a randomized, prospective, multicenter, pilot study comparing acute and long-term results of 
414 orbital atherectomy to balloon angioplasty for calcified femoropopliteal disease. J Invasive

415 Cardiol 2014;26:355-60.

416 25. Rocha-Singh KJ, Zeller T, Jaff MR. Peripheral arterial calcification: prevalence,

417 mechanism, detection, and clinical implications. Catheter Cardiovasc Interv 2014;83:E212-

41820.

419 26. Kobayashi Y, Okura H, Kume T, Yamada R, Kobayashi Y, Fukuhara K, et al. Impact

420 of target lesion coronary calcification on stent expansion. Circ J 2014;78:2209-14.

421 27. Norgren L, Hiatt WR, Dormandy JA, Nehler MR, Harris KA, Fowkes FG, et al. Inter-

422 Society Consensus for the Management of Peripheral Arterial Disease (TASC II). Eur J Vasc

423 Endovasc Surg 2007;33 Suppl 1:S1-75.

424 28. Lanzer P, Boehm M, Sorribas V, Thiriet M, Janzen J, Zeller T, et al. Medial vascular

425 calcification revisited: review and perspectives. Eur Heart J 2014;35:1515-25.

426 29. Pasterkamp G, Borst C, Gussenhoven EJ, Mali WP, Post MJ, The SH, et al.

427 Remodeling of De Novo atherosclerotic lesions in femoral arteries: impact on mechanism of

428 balloon angioplasty. J Am Coll Cardiol 1995;26:422-8.

429 30. Rosenfield K, Jaff MR, White CJ, Rocha-Singh K, Mena-Hurtado C, Metzger DC, et 430 al. Trial of a Paclitaxel-Coated Balloon for Femoropopliteal Artery Disease. N Engl J Med $431 \quad 2015 ; 373: 145-53$.

432 31. Schroeder H, Meyer DR, Lux B, Ruecker F, Martorana M, Duda S. Two-year results

433 of a low-dose drug-coated balloon for revascularization of the femoropopliteal artery:

434 outcomes from the ILLUMENATE first-in-human study. Catheter Cardiovasc Interv

$435 \quad 2015 ; 86: 278-86$.

436 32. Mosseri M, Satler LF, Pichard AD, Waksman R. Impact of vessel calcification on

437 outcomes after coronary stenting. Cardiovasc Revasc Med 2005;6:147-53. 
438 33. Finn AV, Nakazawa G, Joner M, Kolodgie FD, Mont EK, Gold HK, et al. Vascular

439 responses to drug eluting stents: importance of delayed healing. Arterioscler Thromb Vasc 440 Biol 2007;27:1500-10.

441 34. Bosiers M, Torsello G, Gissler HM, Ruef J, Muller-Hulsbeck S, Jahnke T, et al.

442 Nitinol stent implantation in long superficial femoral artery lesions: 12-month results of the

443 DURABILITY I study. J Endovasc Ther 2009;16:261-9.

444 35. Vent PA, Kaladji A, Davaine JM, Guyomarch B, Chaillou P, Costargent A, et al. Bare

445 Metal Versus Paclitaxel-Eluting Stents for Long Femoropopliteal Lesions: Prospective

446 Cohorts Comparison Using a Propensity Score-Matched Analysis. Ann Vasc Surg 2017.

447 36. Byrne RA, Joner M, Kastrati A. Stent thrombosis and restenosis: what have we

448 learned and where are we going? The Andreas Gruntzig Lecture ESC 2014. Eur Heart J

$449 \quad 2015 ; 36: 3320-31$.

450 
Table 1. Demographic data

\begin{tabular}{|c|c|c|c|c|c|}
\hline & $\begin{array}{c}\text { Total } \\
\text { Population } \\
(\mathrm{n}=39)\end{array}$ & $\begin{array}{c}\text { Non } \\
\text { calcified } \\
\text { group } \\
(\mathrm{n}=10)\end{array}$ & $\begin{array}{l}\text { Intermediate } \\
\text { calcifications } \\
\text { group }(n=19)\end{array}$ & $\begin{array}{l}\text { Heavily } \\
\text { calcified } \\
\text { group } \\
(n=10)\end{array}$ & P value \\
\hline Age (mean \pm SD) & $71 \pm 12$ & $70.5 \pm 11.2$ & $71 \pm 12.8$ & $71.4 \pm 12.7$ & 0.96 \\
\hline Gender (male, n, \%) & $24(61.5 \%)$ & $4(40 \%)$ & $12(63.2 \%)$ & $8(80 \%)$ & 0.181 \\
\hline Body Mass index (mean \pm SD) & $24.2 \pm 5$ & $24.1 \pm 4.3$ & $23.2 \pm 5.4$ & $26.6 \pm 4.5$ & 0.25 \\
\hline Active smoking (n, \%) & $12(30.8 \%)$ & $5(50 \%)$ & $6(31.6 \%)$ & $1(10 \%)$ & 0.152 \\
\hline Hypertension (n, \%) & $25(64.1 \%)$ & $6(60 \%)$ & $14(73.7 \%)$ & $5(50 \%)$ & 0.428 \\
\hline Diabetes mellitus (n, \%) & $8(20.5 \%)$ & 0 & $5(26.3 \%)$ & $3(30 \%)$ & 0.198 \\
\hline Renal failure* (yes, n, \%) & $5(12.8 \%)$ & $1(10 \%)$ & $2(10.5 \%)$ & $2(20 \%)$ & 0.733 \\
\hline Hyperlipidemia (n, \%) & $21(53.8 \%)$ & $3(30 \%)$ & $10(52.6 \%)$ & $8(80 \%)$ & 0.080 \\
\hline Double antiplatelet therapy (n, \%) & $13(33.3 \%)$ & $4(40 \%)$ & $7(36.8 \%)$ & $2(20 \%)$ & 0.759 \\
\hline Anti-vitamin K therapy (n, \%) & $1(2.6 \%)$ & 0 & $1(5.3 \%)$ & 0 & 0.583 \\
\hline Statin therapy (n, \%) & 30 (76.9\%) & $8(80 \%)$ & $13(68.4 \%)$ & $9(90 \%)$ & 0.409 \\
\hline ACE inhibitor or ATA II * (n, \%) & $64.1(25 \%)$ & $6(60 \%)$ & $11(57.9 \%)$ & $8(80 \%)$ & 0.475 \\
\hline \multicolumn{6}{|l|}{ Rutherford stages } \\
\hline $3(\mathrm{n}, \%)$ & $14(35.9 \%)$ & $4(40 \%)$ & $6(31.6 \%)$ & $4(40 \%)$ & \\
\hline $4(\mathrm{n}, \%)$ & $16(41 \%)$ & $4(40 \%)$ & $10(52.6 \%)$ & $2(20 \%)$ & 0.461 \\
\hline $5(\mathrm{n}, \%)$ & $9(23.1 \%)$ & $2(20 \%)$ & $3(15.8 \%)$ & $4(40 \%)$ & \\
\hline
\end{tabular}

* defined as an estimated glomerular filtration rate $30<\mathrm{ml} / \mathrm{min} / 1.73 \mathrm{~m}^{-2}$ according to MDRD formula

* ACE: Angiotensin-converting-enzyme ARA II : angiotensin II receptor antagonist 
Table 2. Anatomical and intraoperative data

$\begin{array}{ccccc}\begin{array}{c}\text { Total } \\ \text { Population }\end{array} & \begin{array}{c}\text { Non } \\ \text { calcified }\end{array} & \begin{array}{c}\text { Intermediate } \\ \text { calcifications }\end{array} & \begin{array}{c}\text { Heavily } \\ \text { calcified } \\ \text { group }(\mathrm{n}=10)\end{array} & \text { P value } \\ & \begin{array}{c}\text { group } \\ \text { group }(\mathrm{n}=10)\end{array} & & & \\ & & & & \end{array}$

\begin{tabular}{|c|c|c|c|c|c|}
\hline SFA diameter (mm, mean \pm SD) & $5.4 \pm 1.2$ & $4.6 \pm 0.8$ & $5.2 \pm 1$ & $6.8 \pm 0.8$ & $<0.0001$ \\
\hline Lesion length (mm, mean \pm SD) & $202.1 \pm 103.2$ & $176.9 \pm 79$ & $217.4 \pm 108.1$ & $201.1 \pm 120.8$ & 0.616 \\
\hline SFA occlusion (yes, n, \%) & $28(71.8 \%)$ & $7(70 \%)$ & $13(68.4 \%)$ & $8(80 \%)$ & 0.796 \\
\hline Ca volume lesion $\left(\mathrm{mm}^{3}\right.$, mean $\left.\pm \mathrm{SD}\right)$ & $1076 \pm 1322$ & $5.5 \pm 7.4$ & $870 \pm 701$ & $2702 \pm 1571$ & $<0.0001$ \\
\hline ALu volume lesion $\left(\mathrm{mm}^{3}\right.$, mean $\left.\pm \mathrm{SD}\right)$ & $1996 \pm 1553$ & $1194 \pm 1027$ & $1584 \pm 772$ & $3786 \pm 1895$ & $<0.0001$ \\
\hline Ca volume SFA $\left(\mathrm{mm}^{3}\right.$, mean \pm SD) & $1348 \pm 1428$ & $24.6 \pm 44.1$ & $1196 \pm 854$ & $3141 \pm 1392$ & $<0.0001$ \\
\hline ALu volume SFA ( $\mathrm{mm}^{3}$, mean $\left.\pm \mathrm{SD}\right)$ & $5735 \pm 3041$ & $4651 \pm 2425$ & $4870 \pm 2836$ & $8769 \pm 2107$ & 0.001 \\
\hline Drug eluting stent (yes, n, \%) & $19(48.7 \%)$ & $3(30 \%)$ & $12(63.2 \%)$ & $4(40 \%)$ & 0.193 \\
\hline Stented length (mm, mean \pm SD) & $250 \pm 104$ & $233 \pm 90$ & $267 \pm 108$ & $233 \pm 116$ & 0.611 \\
\hline Number of stents (mean \pm SD ) & $2.5 \pm 1.3$ & $2.4 \pm 1$ & $2.8 \pm 1.2$ & $2 \pm 1$ & 0.22 \\
\hline Stent diameter (mm, mean \pm SD) & $6 \pm 0.6$ & $5.8 \pm 0.8$ & $6.1 \pm 0.5$ & $5.9 \pm 0.6$ & 0.391 \\
\hline Fluoroscopic time (min, mean \pm SD) & $18.5 \pm 12$ & $11.1 \pm 3.9$ & $18.2 \pm 8.2$ & $27.3 \pm 17.6$ & 0.009 \\
\hline Surface-dose product (mGy.m², mean \pm SD) & $2.91 \pm 3.91$ & $1.25 \pm 0.61$ & $3.55 \pm 3.99$ & $3.39 \pm 3.06$ & 0.3 \\
\hline Contrast load (mL, mean \pm SD) & $69.1 \pm 31.5$ & $51.8 \pm 22.3$ & $72.4 \pm 30.7$ & $81.6 \pm 37.4$ & 0.097 \\
\hline
\end{tabular}

* SFA: superficial femoral artery, Ca: calcifications, ALu: arterial lumen 
Table. 3 Influence of calcification on postoperative outcomes during follow-up according to groups (log-rank test)

$\begin{array}{cccc}\begin{array}{c}\text { Occurrence } \\ (\mathrm{n}, \%)\end{array} & \text { Group } 1 & \text { Group } 2 & \text { Group } 3 \\ & & \end{array}$

\begin{tabular}{|c|c|c|c|c|}
\hline Stent thrombosis (in global population) & $10(25.6 \%)$ & \multicolumn{3}{|c|}{$\mathrm{P}$ value of pair comparison } \\
\hline Group 1 (No Ca group) & $4(40 \%)$ & & 0.037 & 0.861 \\
\hline Group 2 (Intermediate Ca group) & $2(10.5 \%)$ & 0.037 & & 0.121 \\
\hline Group 3 (Heavy Ca group) & $4(40 \%)$ & 0.861 & 0.121 & \\
\hline In-stent restenosis & $9(23.1 \%)$ & \multicolumn{3}{|c|}{$P$ value of pair comparison } \\
\hline Group 1 & $4(40 \%)$ & & 0.358 & 0.741 \\
\hline Group 2 & $4(21.1 \%)$ & 0.358 & & 0.520 \\
\hline Group 3 & $1(10 \%)$ & 0.741 & 0.520 & \\
\hline Target lesion revascularization & $17(43.6 \%)$ & \multicolumn{3}{|c|}{$P$ value of pair comparison } \\
\hline Group 1 & 19 (65.5\%) & & 0.113 & 0.735 \\
\hline Group 2 & $5(26.2 \%)$ & 0.113 & & 0.380 \\
\hline Group 3 & $5(50 \%)$ & 0.735 & 0.380 & \\
\hline Target extremity revascularization & $18(46.2 \%)$ & \multicolumn{3}{|c|}{$\mathrm{P}$ value of pair comparison } \\
\hline Group 1 & $6(60 \%)$ & & 0.113 & 0.735 \\
\hline Group 2 & $6(31.6 \%)$ & 0.113 & & 0.380 \\
\hline Group 3 & $6(60 \%)$ & 0.735 & 0.380 & \\
\hline
\end{tabular}




\section{ACCEPTED MANUSCRIPT}

Table. 4 : Factors associated with stent thrombosis by log rank test.

No stent thrombosis
$(\mathrm{n}=29)$$\quad$ Stent thrombosis $(\mathrm{n}=10) \quad$ P value

$(\mathrm{n}=29)$

\begin{tabular}{|c|c|c|c|}
\hline Age (years, mean \pm SD) & $72.5 \pm 11.1$ & $65.9 \pm 13.6$ & 0.213 \\
\hline Body mass index & $23.9 \pm 5.2$ & $25.2 \pm 4$ & 0.468 \\
\hline Gender (male, n, \%)) & $16(55.2 \%)$ & $8(80 \%)$ & 0.155 \\
\hline Active smoking (n, \%) & $10(34.5 \%)$ & $2(20 \%)$ & 0.332 \\
\hline Hypertension (n, \%) & $18(62.1 \%)$ & $7(70 \%)$ & 0.48 \\
\hline Diabetes mellitus (n, \%) & $5(17.2 \%)$ & $3(30 \%)$ & 0.601 \\
\hline Renal failure* (yes, n, \%) & $4(13.8 \%)$ & $1(10 \%)$ & 0.619 \\
\hline Hyperlipidemia (n, \%) & $13(44.8 \%)$ & $8(80 \%)$ & 0.058 \\
\hline Double antiplatelet therapy (n, \%) & $11(37.9 \%)$ & $2(20 \%)$ & 0.473 \\
\hline Anti-vitamin K therapy (n, \%) & $1(3.4 \%)$ & 0 & 0.744 \\
\hline Statin therapy (n, \%) & 22 (75.9\%) & $8(80 \%)$ & 0.581 \\
\hline ACE inhibitor or ATA II * (n, \%) & $18(62.1 \%)$ & $7(70 \%)$ & 0.480 \\
\hline Rutherford stages 3/4/5 & $9(31 \%) / 13(44.8 \%) / 7(24.1 \%)$ & $5(50 \%) / 3(30 \%) / 2(20 \%)$ & 0.549 \\
\hline \multicolumn{4}{|l|}{ Lesion Ca } \\
\hline No Ca (group 1) & $6(60 \%)$ & $4(40 \%)$ & \\
\hline Intermediate Ca (group 2) & 17 (89.5\%) & $2(10.5 \%)$ & 0.109 \\
\hline Heavy Ca (group 3) & $6(60 \%)$ & $4(40 \%)$ & \\
\hline SFA diameter (mm, mean \pm SD) & $5.2 \pm 1.1$ & $6.1 \pm 1.3$ & 0.05 \\
\hline Lesion length (mm, mean \pm SD) & $205.6 \pm 107.7$ & $183.9 \pm 93$ & 0.575 \\
\hline SFA occlusion (yes, n, \%) & $7(70 \%)$ & $13(68.4 \%)$ & 0.796 \\
\hline Drug eluting stent (yes, n, \%) & $3(30 \%)$ & $12(63.2 \%)$ & 0.193 \\
\hline Stented length (mm, mean \pm SD) & $250.3 \pm 109.3$ & $240 \pm 91$ & 0.790 \\
\hline Number of stents (mean \pm SD ) & $2.5 \pm 1.2$ & $2,60 \pm 1.1$ & 0.75 \\
\hline Stent diameter (mm, mean \pm SD) & $6 \pm 0.6$ & $6 \pm 0.7$ & 0.885 \\
\hline
\end{tabular}


Table 5. Results of the multivariate analysis

\begin{tabular}{lccccc}
\hline & coeff & Wald $\chi^{2}$ & $\mathrm{df*}$ & Probability $>\chi^{2}$ & Odds ratio (95\% CI) \\
\hline Intermediate Ca & -1.315 & 6.025 & 1 & 0.014 & $0.27(0.1-0.77)$ \\
Sex (male) & 0.256 & 0.311 & 1 & 0.577 & $1.29(0.53-3.17)$ \\
Hyperlipidemia & 0.412 & 0.828 & 1 & 0.363 & $1.51(0.62-3.67)$ \\
SFA diameter & -0.492 & 3.819 & 1 & 0.051 & $0.61(0.373-1.001)$ \\
& & & & &
\end{tabular}




\section{ACCEPTED MANUSCRIPT}

Fig. 1. CT-images processing: after centerlines extraction (A), a region of interest (purple cylinder, B) is determined and centered around the centerlines. A threshold tool is applied to segment vascular Ca (blue, C-D) and arterial lumen (red, C-D).

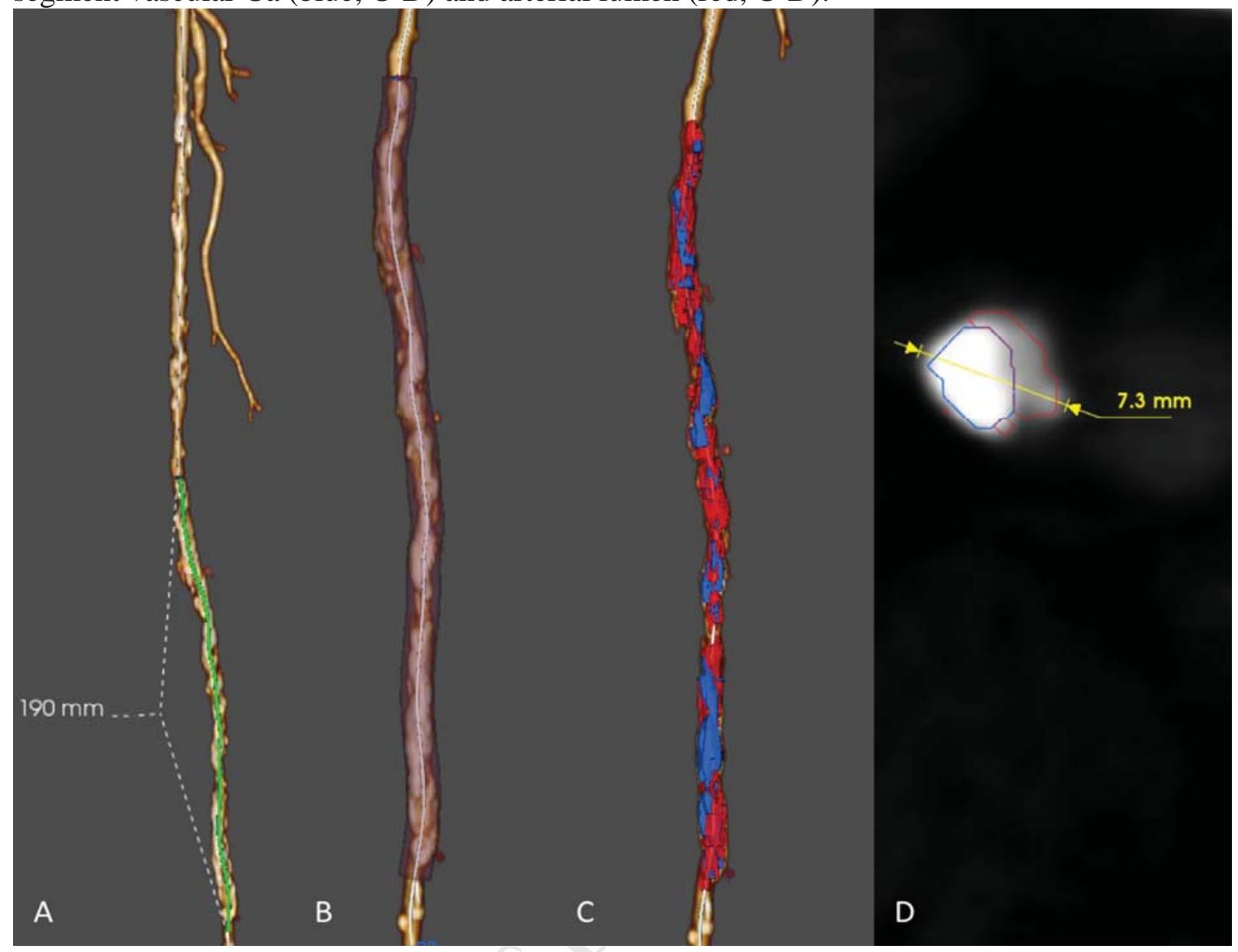


Fig. 2. Correlation between SFA diameter and percentage of Ca

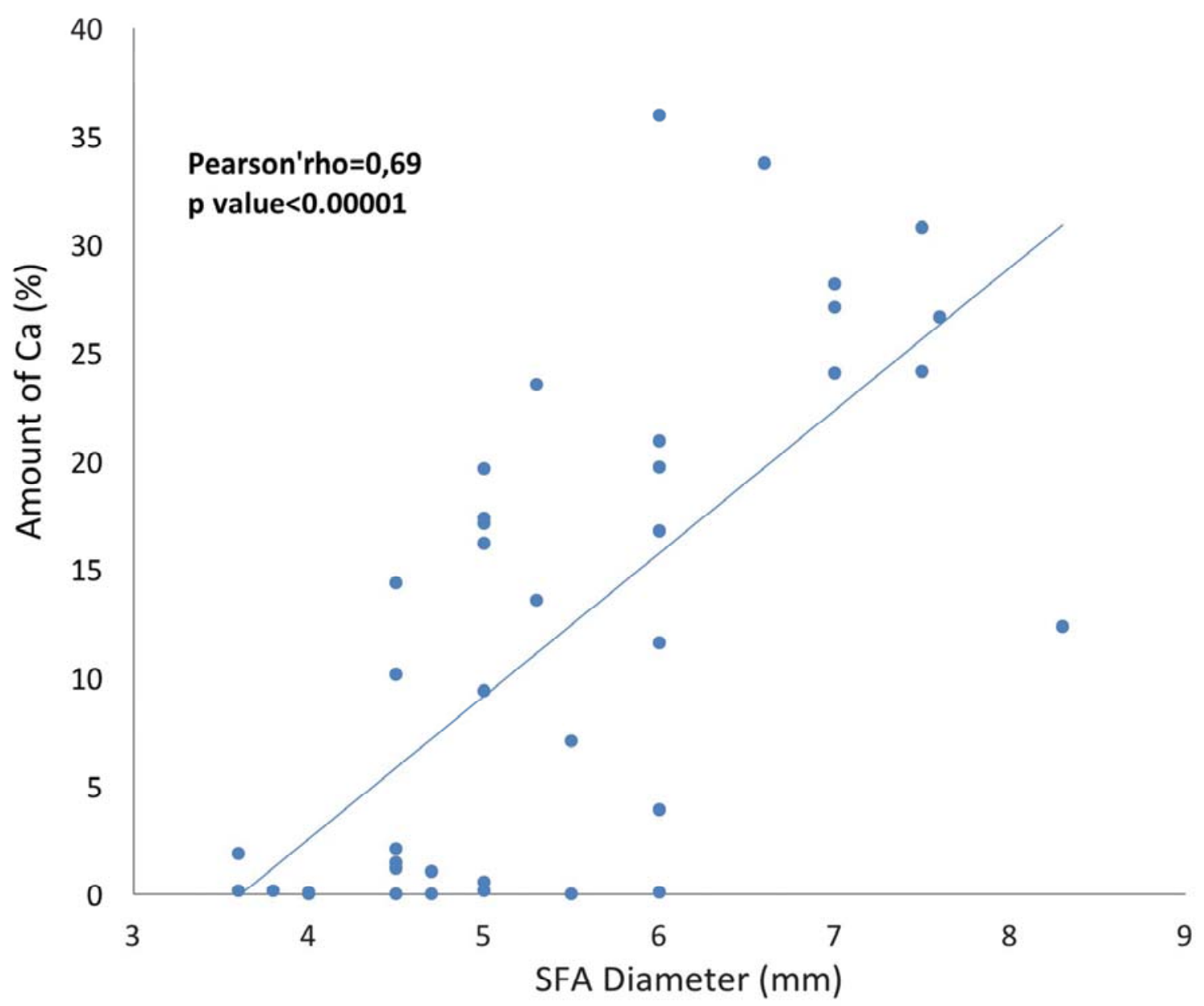


Fig. 3. Analysis of date of thrombosis according to Ca rate.

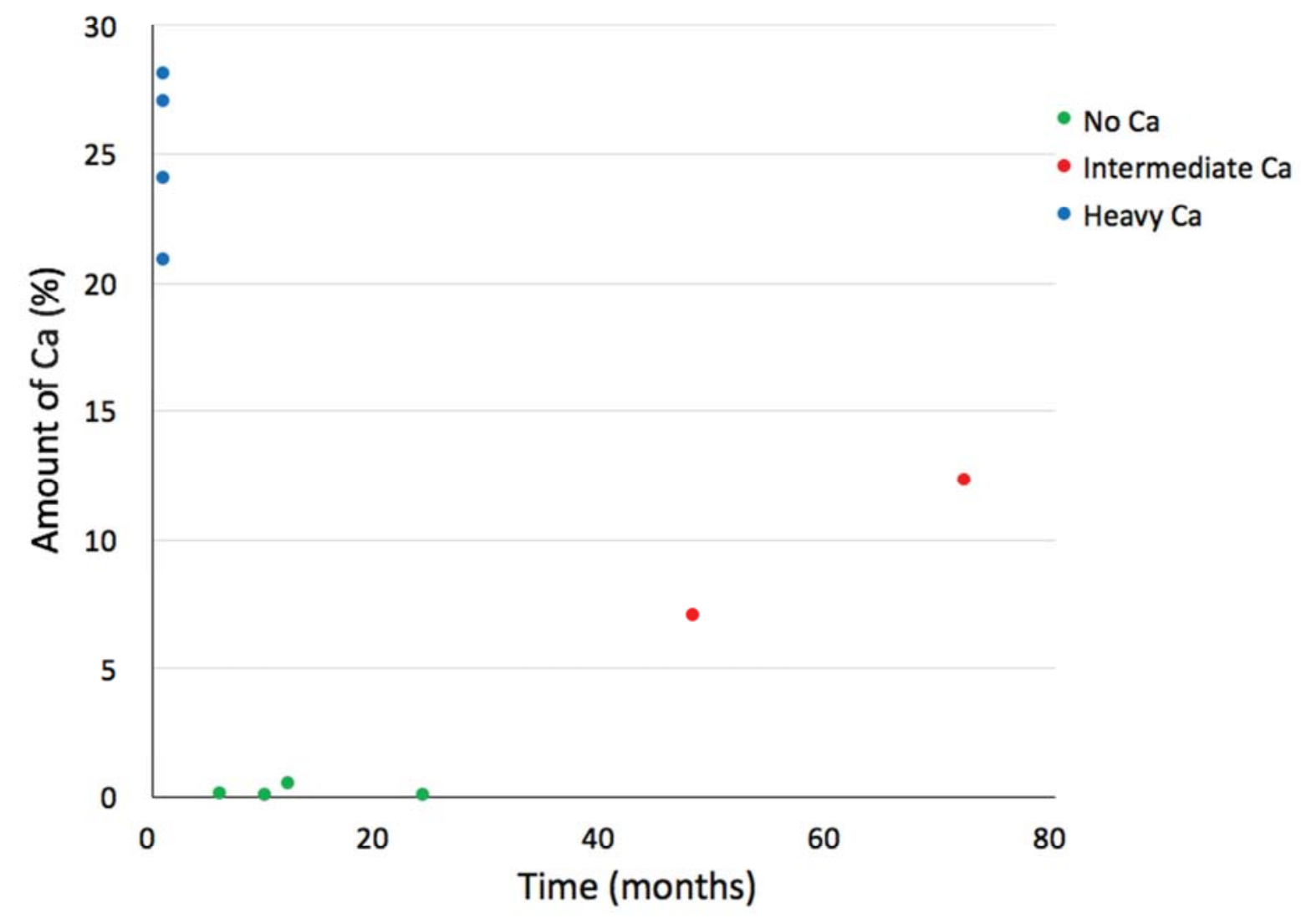

